\title{
Cmambu \\ ФУНКЦИИ ЛИЧНОСТНЫХ РЕСУРСОВ В СИТУАЦИИ ЭКОНОМИЧЕСКОГО КРИЗИСА
}

\author{
Т.Ю. ИВАНОВА
}

${ }^{a}$ Национальньй исследовательский университет «Высшая школа экономики», 101000, Россия, Москва, ул. Мясницкая, д. 20

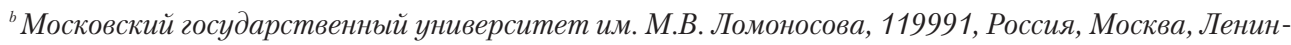
ские горы, Ә. 1

\section{Резюме}

Работа посвящена выявлению вклада личностных ресурсов (смысложизненных ориентаций, оптимизма, жизнестойкости, толерантности к неопределенности, самоэффективности) в динамику субъективного благополучия в условиях экономического кризиса. Личностные ресурсы выполняют в ситуации экономического кризиса фильтрующую и буферную функции, опосредуя как оценку человеком влияния кризиса на его жизнь, так и то, каким образом оценка кризиса сказывается на изменении субъективного благополучия через год. 126 взрослых жителей Москвы участвовали в исследовании отношения к кризису, личностного потенциала и субъективного благополучия в разгар экономического кризиса в мае-июне 2009 г.; через 14-16 месяцев у 86 человек из первоначальной выборки повторно оценивался уровень субъективного благополучия. Было показано, что оценка кризиса как повлиявшего на жизнь в большей степени связана с личностными ресурсами, чем с социодемографическими факторами. Выраженность фильтрующей функции не одинакова: если для осмысленности жизни и копинг-стратегии самоконтроля она подтверждается полностью, то относительно оптимизма, жизнестойкости и копинг-стратегии «планирование» она выражена лишь на уровне тенденции. Буферная функция выражена в большей степени, чем фильтрующая, и выявлена как для каждого ресурса в отдельности, так и для интегрального показателя личностных ресурсов (ИРЛ). Однако буферная функция ИРЛ была выявлена лишь в отношении динамики удовлетворенности жизнью, но не витальности: при низком уровне ИРЛ удовлетворенность жизнью через год значительно более зависит от оценки кризиса, чем при высоком уровне; более того, при высоком уровне личностного потенциала удовлетворенность жизнью при втором замере «парадоксально» выше у тех, кто считает, что кризис повлиял на их жизнь.

Ключевые слова: личностные ресурсы, субъективная оценка влияния экономического кризиса, буферная функция личностных ресурсов, динамика субъективного благополучия.

Исследование осуществлено в рамках Программы фундаментальных исследований НИУ ВШЭ в 2014 г. 
Все бо́льшую популярность в науках о человеке приобретает взгляд, согласно которому полноценный анализ и понимание долгосрочных эффектов экономических и политических явлений требуют учета социальных и психологических процессов, которые развиваются на их фоне (Sirgy et al., 2006). С этой точки зрения экономический кризис может выступать как модель долгосрочной ситуации, связанной с объективными изменениями в жизни людей (потеря работы, снижение уровня финансового благополучия и т.п.), угрозой возможных изменений (вследствие экономической нестабильности) и выбором как личностной позиции по отношению к кризису (например, «поддаваться ли панике»), так и стратегий совладания с возможным стрессом.

О важной роли субъективной оценки кризиса и ожиданий от будущего в финансовом поведении свидетельствуют и экономические исследования кризиса 2008-2009 гг. в России (Ибрагимова, Кузина, 2009), который выступал в качестве эмпирической модели и в нашем исследовании: хотя ожидания и представления людей не полностью соответствуют их реальным заработкам, они связаны с готовностью к тратам и изменениям в поведении с течением времени.

Следует отметить, что идея использования нестабильной внешней ситуации как модели психологического стресса и кризиса, своеобразного «естественного эксперимента» не нова (например: Maddi, 1987). Ее теоретические основания восходят, с одной стороны, к транзактной модели стресса, учитывающей роль оцен- ки, в том числе предвосхищающей, сложившейся ситуации и ресурсов, доступных для совладания (Lazarus, 2006; Folkman et al., 1979). С другой стороны, немаловажный вклад в модели такого рода внесли гуманистическая и экзистенциальная традиции, в перспективе которых жизненная ситуация рассматривается как ставящая своеобразный «вопрос» перед человеком о нем самом, а человек выбирает: «слышать» и «выдерживать» эти вопросы (Тиллих, 1995; Франкл, 1990), - что может приводить к актуализации и развитию принципиально новых возможностей (например, см. понятие «трансформационное совладание» - Maddi, 2001). В отечественной психологии характерным примером является концепция Ф.Е. Василюка (1984), который определяет критическую ситуацию как ситуацию невозможности реализации внутренних необходимостей своей жизни (мотивов, стремлений, ценностей и пр.). В крайнем своем проявлении такого рода ситуации требуют участия личностной рефлексии и пересмотра психологических оснований своей деятельности (Зейгарник и др., 1989). В целом это указывает на возможность положительной функции кризисных ситуаций в жизни человека и ключевую роль личностных факторов в понимании и переживании трудных жизненных ситуаций.

Традиционно личностные ресурсы рассматриваются в контексте совладания как обеспечивающие возможность успешного преодоления стрессов и совладания с жизненными трудностями (Baltes, 1987; Бодров, 2000; Лазарус, 1970; Maddi, Koshala, 1984; Hobfoll, 2011; Муздыбаев, 1998; 
Крюкова, 2004), как средства (инструменты), используемые для трансформации взаимодействия со стрессогенной ситуацией, способствующие психологической устойчивости (Водопьянова, 2009). Существующие эмпирические данные свидетельствуют в пользу важной роли личностных ресурсов в сохранении психологического благополучия в стрессогенных ситуациях: проблемы, связанные с трудовой деятельностью (Демин, 2004; Cole et al., 2009); материальная недостаточность (Муздыбаев, 2001); экономическая нестабильность и депривация (Shteyn et al., 2003); последствия природных катастроф (Benight, Harper, 2002; Ironson et al., 1997) и др.

Например, по данным 4-летнего лонгитюдного исследования (Holahan, Moos, 1991), вклад личностных (уверенность в себе, готовность к действиям) и социальных (поддержка со стороны семьи) ресурсов в снижении уровня депрессии зависит от стрессогенности ситуации: при низком уровне стресса влияние прямое, при высоком - в качестве медиатора этой связи выступают адаптивные копинг-стратегии. Позже данный эффект получил поддержку в отношении социальных изменений (Grumer, Pinquart, 2011): оптимизм и социальная поддержка предотвращают развитие депрессивных симптомов в условиях повышенных социальных требований (на работе, в семье, в общении). А исследование психологических последствий экономической нестабильности для российских женщин (Shteyn et al., 2003) показало, что потери в результате экономического кризиса связаны с повышением психологического стресса как напрямую, так и косвенно - их влияние выше при низком уровне компетентности и воспринимаемой социальной поддержки.

Следует отметить, что к настоящему времени в психологии личности накоплен широкий круг эмпирических данных, показывающих, что личностные ресурсы выступают не только в качестве предикторов, а в качестве модераторов и медиаторов, опосредствуя связь между стрессогенными событиями и психологическим состоянием человека (Wise, Stake, 2002; Xanthopoulou et al., 2007; Luthans et al., 2008; Mastenbroek, 2014). Описаны различные эффекты, которые личностные ресурсы оказывают на психологическое благополучие, выполняя роль регуляторов различных процессов: оценки (например, благодаря личностным ресурсам стрессогенная ситуация оценивается как не угрожающая, а возможности совладания - как достаточные, что препятствует развитию стресса) (Jerusalem, Schwarzer, 1992; Schwarzer, 1999), контроля и управления поведением, от их уровня зависит реакция на стресс и особенности совладания (например, личностные ресурсы способствуют использованию в условиях стресса адаптивных копингстратегий - Thoits, 1994; Baumeister et al., 2007; Сергиенко, 2009), предохранения от стрессов, поддержания психологического благополучия и предотвращения его снижения (Shteyn et al., 2003; Turner et al., 2004; Benight, Harper, 2002; Cole et al., 2009; Culbertson et al., 2010).

Данная работа посвящена исследованию функций личностных ресурсов в ситуации экономического 
кризиса. Целью нашего исследования является изучение функциональной роли личностных ресурсов в ситуации угрозы благополучию (на модели экономического кризиса).

Предметом исследования являются функции, которые выполняют личностные ресурсы в поддержании психологического благополучия при столкновении со стрессовой ситуацией, вызванной экономическим кризисом.

В рамках данной статьи мы рассмотрим две функции личностных ресурсов, которые назовем: фильтрующая и буферная - в соответствии с той ролью, которую они выполняют относительно психологического благополучия.

Фильтрующая функция. Личностные ресурсы участвуют в процессе когнитивной оценки степени влияния кризиса, за счет придания личностного смысла ситуации. Сами по себе они не несут оценку, а способствуют коррекции информации на входе, выполняя функцию «фильтра». В стрессогенной ситуации они способствуют оценке ситуации как менее угрожающей (и в отношении текущей ситуации, и в отношении ее развития в будущем), а также оценке своих ресурсов, необходимых, чтобы справиться с кризисом, как достаточных. При этом доминирующий вектор влияния будет различаться для разных конструктов. В частности, оптимизм в большей степени связан с оценкой будущего и характеризуется предрасположенностью к позитивной переоценке событий, жизнестойкость связана с оценкой происходящих событий, самоэффективность - с оценкой собственной способности совладать с происходя- щими событиями и способности к эффективной деятельности. Фильтрующая функция является, в частности, и защитной, так как проявляется в снижении чувствительности и уязвимости к проблеме кризиса, в результате чего эта потенциальная проблема не только отсутствует в сознании человека (отрицается), но и не проявляется в каких-либо нарушениях его жизнедеятельности и эмоционального состояния.

Буферная функция. Личностные ресурсы препятствуют развитию стресса и предотвращают снижение психологического благополучия под влиянием стрессогенных событий, связанных с экономическим кризисом. Так, широкий спектр негативных переживаний, связанных с экономическим кризисом (как по поводу произошедших, так и по поводу возможных в будущем изменений), приводит к снижению субъективного благополучия. Однако личностные ресурсы будут препятствовать ухудшению состояния в стрессогенных условиях; соответственно на эмпирическом уровне личностные ресурсы должны выступать в качестве модератора, опосредствующего вклад оценки влияния экономического кризиса в изменение субъективного благополучия с течением времени.

Таким образом, мы предполагаем, что:

1) личностные ресурсы выполняют фильтрующую функцию, опосредствуя субъективное восприятие степени влияния экономического кризиса на сознание и деятельность людей (гипотеза 1);

2) личностные ресурсы выполняют буферную функцию, поддерживая 
психологическое благополучие и предотвращая его снижение. В случае ощущения влияния кризиса $\mathrm{y}$ респондентов с высокими показателями личностных ресурсов психологическое благополучие не изменится с течением времени в сравнении с теми, у кого показатели личностных ресурсов низкие (гипотеза 2).

\section{Процедура и выборка}

Исследование проводилось в два этапа. Первый этап проводился в течение двух месяцев (май-июнь) 2009 г. Жителям г. Москвы различных профессий, социального статуca, имеющим разный уровень достатка и качества жизни, предлагали принять участие в психологическом исследовании и заполнить тестовую батарею, состоящую из набора психологических методик и авторской анкеты. Количество участников первого этапа составило 127 человек, 60 мужчин и 67 женщин

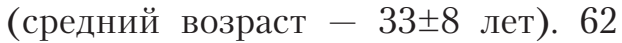
человека (48\%) состояли на момент исследования в браке, 16 человек (12\%) - в разводе, 49 человек (38\%) были холосты/не замужем. У 75 испытуемых (59\%) не было детей, у 37 (29\%) - был один ребенок, у 15 $(11 \%)$ - два и более детей. Большинство респондентов работали в организациях частного сектора (79 человек, 62\%); 18 (14\%) занимались частным предпринимательством или были собственниками бизнеса; 8 (6\%) человек были заняты в государственном секторе; 8 (6\%) не работали или были на пенсии; $14(11 \%)$ проходили курс обучения. Большинство респондентов были с высшим образованием (83 человека,
$65 \%$ ) или ученой степенью (21 человек, 16\%). 61 человек (48\%) оценивали финансовый достаток как средний, 51 человек (40\%) - как низкий или относительно низкий, 15 испытуемых (11\%) - как высокий. 27 респондентов отметили, что финансовое положение в их семье зависит полностью или в основном от них (21\%), 44 человека (34\%) - что частично от них, 56 (44\%) - в незначительной степени или не зависит. Важно отметить, что эти ответы не зависели от финансового положения респондентов (по критерию Хи-квадрат Пирсона).

На втором этапе через 14-16 месяцев после первого тестирования, осенью 2010 г. участникам было предложено повторно заполнить несколько меньшую по объему батарею тестов. Из первоначальной выборки 15 человек отказались от участия в повторном опросе, 26 человек не удалось разыскать. Таким образом, во втором срезе выборка составила 86 человек (уровень ответов 67\%). С целью контроля фактора отказа от продолжения участия в исследовании проводилось сравнение возраста (t-критерий Стьюдента), пола, образования, семейного и финансового положения, количества детей, меры участия в финансовом положении семьи, профессии (Хиквадрат Пирсона) у респондентов, продолживших участие в исследовании, и респондентов, не принимавших участия во втором этапе. Единственные различия касались профессии: не работающие респонденты практически все участвовали во втором срезе, и общее сокращение выборки произошло в основном за счет работающих. Таким образом, на 
втором этапе выборка осталась достаточно репрезентативной по отношению к исходной.

\section{Методический инструментарий}

Первый этап исследования включал заполнение следующих инструментов.

A. Авторская анкета включала 15 вопросов с закрытым списком возможных ответов и использовалась для выявления социодемографических факторов и субъективной оценки изменений, произошедших в жизни испытуемых за последние полгода, а также влияния экономического кризиса на их жизнь. Первая часть включала 9 вопросов, касающихся возраста, пола, образования, финансового положения, вклада, который респондент вносит в семейный бюджет, семейного положения, наличия и количества детей, профессионального статуса. Вторая часть включала 6 вопросов, предположительно представляющих косвенные индикаторы неблагополучия:

1. Изменение профессиональных перспектив оценивалось при помощи вопроса: «За последние полгода ваши профессиональные перспективы (доходы, карьера, профессиональное образование)... заметно улучшились, слегка улучшились, не изменились, слегка ухудшились, заметно ухудшились».

2. Для оценки изменений в уровне доходов использовался следующий вопрос: «Ваши реальные доходы за последние полгода... заметно увеличились, слегка увеличились, не изменились, слегка уменьшились, заметно уменьшились».
3. Изменение в самочувствии оценивалось при помощи вопроса: «Последние полгода вы чувствуете себя... лучше, чем раньше; так же хорошо, как раньше; нормально, как всегда; так же плохо, как раньше; хуже, чем раньше».

4. Для оценки изменений в возможностях отдыха использовался вопрос: «В этом году ваши возможности отдыха... значительно лучше, чем раньше; немного лучше, чем раньше; такие же, как и раньше; немного хуже, чем раньше; сильно хуже, чем раньше».

5. Кроме того, в качестве индикатора неблагополучия был включен вопрос: «Количество употребляемого вами алкоголя (иных стимуляторов)... возросло, не изменилось, уменьшилось, никогда не употреблял».

6. Субъективная оценка влияния кризиса на жизнь проводилась при помощи вопроса: «На ваш взгляд, насколько экономический кризис повлиял на вашу жизнь... сильно повлиял, отчасти повлиял, вряд ли повлиял, никак не повлиял».

Б. Психодиагностические методики

1. Шкала удовлетворенности жизнью (SWLS; Diener et al., 1985; Осин, Леонтьев, 2008) - скрининговая методика оценки общей удовлетворенности жизнью.

2. Опросник диспозиционной витальности (Ryan, Frederick, 1997; Александрова, 2011), предназначенный для определения диспозиционной витальности как черты личности.

3. Тест смысложизненных ориентаций (СЖО; Леонтьев, 1992) направлен на диагностику различных аспектов переживания осмысленности жизни и включает пять субшкал: 
цели в жизни, процесс жизни или интерес и эмоциональная насыщенность жизни, результативность жизни или удовлетворенность самореализацией, локус контроля - Я, локус контроля - жизнь или управляемость жизнью.

4. Опросник толерантности к неопределенности (MSTAT-I; McLain, 1993; Луковицкая, 1998) разработан для оценки толерантности к неопределенности как способности переносить неопределенные и неоднозначные ситуации.

5. Тест диспозиционного оптимизма (LOT; Scheier, Carver, 1985; Гордеева и др., 2010). Оптимизм - обобщенные ожидания того, что в будущем будут скорее происходить хорошие события, чем плохие; пессимизм - выраженность более негативных ожиданий относительно будущего.

6. Тест жизнестойкости (Maddi, Khoshaba, 2001; Леонтьев, Рассказова, 2006) направлен на диагностику системы диспозиций, способствующих преодолению стресса. Включает три шкалы: вовлеченность, контроль и принятие риска.

7. Опросник общей самоэффективности (OOSE; Шварцер и др., 1996) измеряет общую уверенность в своих силах добиться поставленной цели.

8. Опросник Способы совладающего поведения (ССП; Lazarus, Folkman, 1984; Вассерман и др., 2009) включает восемь шкал, соответствующих следующим способам преодоления стресса: конфронтация, дистанцирование, самоконтроль, поиск социальной поддержки, принятие ответственности, избегание, планирование решения проблемы, положительная переоценка.
На втором этапе респонденты повторно отвечали на вопросы анкеты, а также заполняли шкалу удовлетворенности жизнью и опросник диспозиционной витальности с целью выявления изменения в их субъективном благополучии.

Переходя к операционализации конструктов личностных ресурсов и субъективного благополучия, следует сделать важную оговорку: поскольку изменения в уровне витальности и субъективного благополучия зависят от их исходного состояния, проводился дополнительный статистический контроль этих переменных с целью выявить независимый от него вклад личностных ресурсов в изменения удовлетворенности жизнью и витальности.

\section{Результаты}

Результать первого замера

\section{Субъективная оценка влияния кри- зиса и косвенные индикаторы не- благополучия}

По данным первого замера, 13 респондентов (10.2\%) считали, что кризис никак не повлиял на их жизнь, 24 человека (18.9\%) - что вряд ли повлиял, 80 человек (63.0\%) - отчасти повлиял и 10 человек (7.9\%) сильно повлиял. В связи с небольшим количеством респондентов в выделенных подгруппах в дальнейшем использовалось деление на две основные группы: считающих, что кризис повлиял на их жизнь (отчасти или сильно - 90 человек, 70.9\%), и отрицающих его существенное влияние (37 человек, 29.1\%). 
Что касается косвенных индикаторов неблагополучия (таблица 1), в среднем респонденты отмечали ухудшение или неизменность финансовой ситуации и возможностей отдыха, улучшение или неизменность самочувствия. В отношении профессиональных перспектив ответы «ухудшились/улучшились/не изменились» распределились практически равномерно. Практически никто не указал на увеличение употребления алкоголя. По всем индикаторам, кроме употребления алкоголя, респонденты, ощущающие влияние кризиса, отмечали значимо более негативные изменения, нежели респонденты, не заметившие влияния кризиса на свою жизнь: они чаще говорили о негативных изменениях в профессиональных перспективах, финансовом благополучии и отдыхе и отмечали отсутствие изменения самочувствия (тогда как рес- понденты, не заметившие влияния кризиса, были склонны говорить об улучшении самочувствия за последние полгода).

Социодемографические факторы субъективной оценки влияния кризиса

Субъективная оценка влияния кризиса на жизнь не зависела от пола, возраста, семейного положения, уровня образования, количества детей, вклада в финансовое благополучие семьи и финансового благосостояния. Однако она была связана с субъективными оценками финансового благополучия $\left(\chi^{2}=6.2, \mathrm{df}=2, p<.05\right)$ : так, о влиянии кризиса на свою жизнь говорили $68.6 \%$ респондентов, оценивших свое финансовое состояние как низкое, 78.7\% из тех, кто оценил свое финансовое положение как среднее, и лишь 46.7\% субъективно

Таблица 1

Изменения в косвенных индикаторах благополучия на последние полгода (субъективные оценки)

\begin{tabular}{|l|c|c|c|c|}
\hline \multicolumn{1}{|c|}{$\begin{array}{c}\text { Косвенные } \\
\text { индикаторы } \\
\text { неблагополучия }\end{array}$} & $\begin{array}{c}\text { Ухудшились } \\
\text { (в отношении } \\
\text { алкоголя - } \\
\text { увеличились) }\end{array}$ & $\begin{array}{c}\text { Не } \\
\text { изменились }\end{array}$ & $\begin{array}{c}\text { Улучшились } \\
\text { (в отношении } \\
\text { алкоголя - } \\
\text { уменьшились) }\end{array}$ & $\begin{array}{c}\text { Сравнение тех, } \\
\text { кто ощутил влия- } \\
\text { ние кризиса, и } \\
\text { тех, кто не ощу- } \\
\text { тил: } \chi^{2} \text { (df = 2) }\end{array}$ \\
\hline $\begin{array}{l}\text { Профессиональные } \\
\text { перспективы }\end{array}$ & $34(26.8 \%)$ & $46(36.2 \%)$ & $47(37.0 \%)$ & $7.1^{*}$ \\
\hline Доходы & $59(46.5 \%)$ & $51(40.2 \%)$ & $17(13.4 \%)$ & $8.5^{*}$ \\
\hline Самочувствие & $10(7.9 \%)$ & $85(66.9 \%)$ & $32(25.2 \%)$ & $9.8^{* *}$ \\
\hline $\begin{array}{l}\text { Возможности } \\
\text { отдыха }\end{array}$ & $42(33.1 \%)$ & $69(54.3 \%)$ & $16(12.6 \%)$ & $10.5^{* *}$ \\
\hline $\begin{array}{l}\text { Употребление } \\
\text { алкоголя }\end{array}$ & $7(5.5 \%)$ & $101(79.5 \%)$ & $19(15.0 \%)$ & 2.4 \\
\hline
\end{tabular}

${ }^{*} p<.05,{ }^{* *} p<.01$. 
состоятельных людей. Иными словами, о влиянии кризиса чаще говорили респонденты, считающие себя плохо и средне обеспеченными. Отмечено отсутствие значимых связей между оценкой влияния кризиса и субъективным изменением профессиональных перспектив и доходов. Оценки изменений в различных сферах за последнее полгода от социодемографических факторов также не зависели.

\section{Роль личностных ресурсов в субъ- ективной оценке влияния кризиса}

Субъективная оценка влияния кризиса на жизнь практически не зависит от социодемографических факторов. Однако она связана с личностными ресурсами и благополучием. Так, у респондентов, не заметив- ших влияния кризиса на свою жизнь, был значимо выше уровень диспозиционной витальности и удовлетворенности жизнью, а также отдельные субшкалы СЖО - процесс и жизненный результат. Напротив, у респондентов, считавших, что кризис повлиял на их жизнь, более выражен копинговый механизм самоконтроля (см. таблицу 2). Значимых различий по жизнестойкости, толерантности к неопределенности, оптимизму, самоэффективности, подавляющему большинству копингов, общему баллу осмысленности жизни и некоторым субшкалам СЖО между этими двумя группами выявлено не было, хотя в отдельных случаях различия достигали уровня статистической тенденции.

Данные, приведенные в таблице 2, позволяют предположить сравнительную независимость оценки влияния

Таблица 2

Роль личностных ресурсов в субъективной оценке влияния кризиса (указаны только значимые различия и различия на уровне тенденции)

\begin{tabular}{|l|c|c|c|c|c|c|}
\hline \multirow{2}{*}{\multicolumn{1}{|c|}{ Личностные ресурсы }} & \multicolumn{2}{c|}{$\begin{array}{c}\text { Кризис не } \\
\text { повлиял }\end{array}$} & \multicolumn{2}{c|}{$\begin{array}{c}\text { Кризис } \\
\text { повлиял }\end{array}$} & \multirow{2}{*}{$\boldsymbol{t}$} & \multirow{2}{*}{$\boldsymbol{p}$} \\
\cline { 1 - 5 } & $\mathrm{M}$ & $\mathrm{SD}$ & $\mathrm{M}$ & $\mathrm{SD}$ & & \\
\hline Диспозиционная витальность & 34.2 & 8.7 & 30.8 & 6.6 & 2.2 & .03 \\
\hline Оптимизм & 60.1 & 7.5 & 57.3 & 8.5 & 1.8 & .08 \\
\hline $\begin{array}{l}\text { Смысложизненные ориентации } \\
\text { (общй балл) }\end{array}$ & 110.0 & 13.6 & 105.1 & 14.5 & 1.8 & .08 \\
\hline СЖО - процесс & 33.3 & 5.1 & 30.7 & 5.4 & 2.5 & .01 \\
\hline СЖО - результат & 28.8 & 4.5 & 27.0 & 3.7 & 2.4 & .02 \\
\hline СЖО - локус контроля - жизнь & 33.0 & 4.9 & 30.9 & 5.6 & 1.9 & .06 \\
\hline Жизнестойкость - вовлеченность & 40.4 & 6.7 & 38.0 & 6.5 & 1.9 & .06 \\
\hline Удовлетворенность жизнью & 24.3 & 5.4 & 21.8 & 5.6 & 2.3 & .03 \\
\hline Совладание - самоконтроль & 12.7 & 3.2 & 13.9 & 2.8 & -2.1 & .04 \\
\hline Совладание - планирование & 12.2 & 3.2 & 13.3 & 2.7 & -2.0 & .05 \\
\hline
\end{tabular}


кризиса от личностных ресурсов. Действительно, достаточным условием субъективного благополучия, независимо от ресурсов личности, выступают благоприятные обстоятельства (или их восприятие как благоприятных для себя); если же внешняя ситуация не вполне благоприятна, сохранять высокий уровень психологического благополучия позволяет наличие выраженных личностных ресурсов, обеспечивающих контроль над ситуацией, своими переживаниями и задающих возможности преодоления негативных последствий этой ситуации. Это означает, что личностные ресурсы сказываются в большей степени на благополучии человека в условиях негативной оценки влияния кризиса и в меньшей степени - на самой оценке влияния кризиса.

\section{Вклад личностных ресурсов и субъ- ективной оценки кризиса в виталь- ность и субъективное благополучие}

В соответствии с поставленными задачами мы предполагали, что личностные ресурсы не только связаны с субъективной оценкой кризиса, но и определяют то, как эта оценка скажется на благополучии (т.е. выполняют функцию опосредствования).

Для проверки этой гипотезы на первом этапе мы факторизовали переменные, которые, согласно теоретической модели и предыдущим исследованиям личностного потенциала (Леонтьев, 2011), могут быть отнесены к личностным ресурсам, такие, как жизнестойкость, толерантность к неопределенности, осмысленность жизни, оптимизм и самоэффективность. Мы предпола- гали, что на основании факторного анализа может быть выделен единый фактор ресурсов личности. По результатам был выделен один фактор с собственным значением, превышающим единицу (2.5), который объяснял $50.0 \%$ дисперсии, что на данном этапе мы считаем достаточным для того, чтобы использовать его в качестве интегрального показателя в дальнейшей обработке данных. С достаточными факторными нагрузками (0.53-0.86 по модулю) в фактор входят оптимизм, осмысленность жизни, жизнестойкость, толерантность к неопределенности. Самоэффективность входит в фактор с небольшой (Наследов, 2004) положительной нагрузкой (0.41). На основании этих результатов мы ввели комплексную переменную интегрального ресурса личности (ИРЛ): при этом факторные нагрузки использовались для определения весов коэффициентов регрессионного уравнения.

На втором этапе анализировались вклады личностных ресурсов (ИРЛ) и субъективной оценки кризиса в удовлетворенность жизнью и витальность. Для этого проводилась серия анализов модерации - метода, основанного на иерархическом регрессионном анализе и позволяющего оценить вклад как отдельных переменных, так и взаимодействия между ними (Field, 2005). Переменная наличия/отсутствия влияния кризиса по субъективным оценкам кодировалась как 1 (есть влияние) или 0 (нет влияния); затем значения ИРЛ и переменной субъективной оценки влияния кризиса перемножались. В итоге получалась вторичная переменная, характеризующая 
взаимодействие личностных ресурсов и субъективной оценки влияния кризиса. Далее для двух зависимых переменных (удовлетворенность жизнью и витальность) проводился иерархический регрессионный анализ: на первом шаге в модель в качестве независимой была включена переменная личностных ресурсов; на втором к ней добавлялась переменная оценки кризиса; на третьем переменная, характеризующая взаимодействие между ними. В случае, если субъективная оценка кризиса имеет собственный (независимый от личностных ресурсов) вклад в дисперсию удовлетворенности жизнью и витальности, второй шаг должен приводить к значимому увеличению процента объясняемой дисперсии $R^{2}$, а в случае, если имеет место взаимо- действие переменных - такое увеличение должно происходить на третьем шаге.

Как и ожидалось в соответствии c ранними данными (Леонтьев, 2011), и удовлетворенность жизнью, и витальность тесно связаны с личностными ресурсами. Однако полученные данные позволяют предполагать, что независимо от этого негативная оценка респондентами влияния кризиса на их жизнь может быть связана со снижением витальности и со снижением удовлетворенности жизнью, хотя эти связи достигают лишь уровня тенденции (таблица 3). Не выявлено влияния взаимодействия личностных ресурсов и субъективной оценки кризиса на удовлетворенность жизнью и витальность.

Таблииа 3

Вклад оценки кризиса в удовлетворенность жизнью и витальность: независимый от личностных ресурсов и опосредствованный личностными ресурсами (результаты анализа модерации)

\begin{tabular}{|c|c|c|c|c|}
\hline \multirow{3}{*}{ Переменные в модели } & \multicolumn{4}{|c|}{ Зависимая переменная } \\
\hline & \multicolumn{2}{|c|}{ Удовлетворенность жизнью } & \multicolumn{2}{|c|}{ Витальность } \\
\hline & $\triangle R^{2}$ & $\beta$ & $\triangle R^{2}$ & $\beta$ \\
\hline $\begin{array}{c}\text { Шаг } 1 \\
\text { ИРЛ }\end{array}$ & $.32^{* *}$ & $.57^{* *}$ & $.34^{* *}$ & $.58^{* *}$ \\
\hline $\begin{array}{l}\text { Шаг } 2 \\
\text { ИРЛ } \\
\text { Оценка кризиса }\end{array}$ & $.02^{\mathrm{T}}$ & $\begin{array}{c}.55^{* *} \\
-.12^{\mathrm{T}}\end{array}$ & $.02^{\mathrm{T}}$ & $\begin{aligned} & .56^{* *} \\
- & .14^{\mathrm{T}}\end{aligned}$ \\
\hline $\begin{array}{l}\text { Шаг } 3 \\
\text { ИРЛ } \\
\text { Оценка кризиса } \\
\text { Взаимодействие ИРЛ и оценки кризиса }\end{array}$ & .01 & $\begin{aligned} & .41^{* *} \\
- & 13^{\mathrm{T}} \\
- & .17\end{aligned}$ & .01 & $\begin{aligned} & .68^{* *} \\
- & .13^{\mathrm{T}} \\
- & .14\end{aligned}$ \\
\hline $\begin{array}{l}\text { Общий процент объясняемой } \\
\text { дисперсии } R^{2}\end{array}$ & \multicolumn{2}{|c|}{$.34^{* *}$} & \multicolumn{2}{|c|}{$.36^{* *}$} \\
\hline
\end{tabular}

${ }^{\mathrm{T}} p<0.1,{ }^{*} p<0.05,{ }^{* * *} p<0.01$. 
Результать второго замера

\section{Вклад личностных ресурсов и субъ- ективной оценки кризиса в изме- нение витальности и удовлетворен- ности жизнью через год}

Целью данного этапа обработки данных было выявление вклада личностных ресурсов (субъективной оценки кризиса и их взаимодействия) в то, каким образом изменяются удовлетворенность жизнью и витальность через год после первого замера. По сравнению с предыдущим этапом здесь возникает дополнительная трудность: и удовлетворенность жизнью, и витальность - стабильные характеристики, и их уровень при втором замере сильно коррелирует с их уровнем при первом замере. Кроме того, изменения в удовлетворенности жизни и витальности могут зависеть не только от их уровня в начале исследования, но и от взаимодействия их уровня в начале исследования с субъективными оценками кризиса. Например, вне всякой зависимости от личностных ресурсов потенциала у витальных и удовлетворенных людей субъективная оценка ситуации как кризисной не приводит к изменениям в их благополучии, а у людей недовольных вызывает еще большее резкое снижение удовлетворенности и витальности. Переходя к операционализации конструктов личностных ресурсов и субъективного благополучия, следует сделать важную оговорку: поскольку изменения в уровне витальности и субъективного благополучия зависят от их исходного состояния, проводился дополнитель- ный статистический контроль этих переменных - с целью выявить независимый от него вклад личностных ресурсов в изменения удовлетворенности жизнью и витальности.

Для того чтобы учесть вклад перечисленных дополнительных факторов, каждый из двух выполненных нами анализов модерации (для предсказания удовлетворенности жизнью и для предсказания витальности) состоял из пяти шагов. На первом шаге в анализ включалась сама зависимая переменная, но при первом замере, т.е. мы контролировали зависимость изменений удовлетворенности жизнью и витальности от того, какими они были в прошлом. На втором шаге в модель добавлялась переменная субъективной оценки кризиса. На третьем - переменная, характеризующая взаимодействие субъективной оценки кризиса и зависимой переменной при первом замере (например, произведение удовлетворенности жизнью при первом замере и субъективной оценки кризиса). Четвертый шаг включал переменную личностных ресурсов, пятый - переменную, характеризующую взаимодействие личностных ресурсов и субъективной оценки кризиса. Если личностные ресурсы опосредствуют влияние субъективной оценки кризиса на изменение субъективного благополучия - независимо от самой оценки и предшествующего уровня благополучия, - пятый шаг модели должен приводить к значимому увеличению процента объясняемой дисперсии $R^{2}$.

В обоих случаях показатели удовлетворенности жизнью и витальности при первом замере тесно связаны с показателями при втором замере 
(таблица 4). После статистического контроля этого эффекта субъективная оценка кризиса не сказывается напрямую на изменении благополучия. Однако добавление в модель взаимодействия витальности и субъективной оценки кризиса приводит к увеличению процента объясняемой дисперсии на уровне тенденции. Для лучшей иллюстрации этого эффекта мы разделили респондентов на группы с высоким и низким изначальным уровнем витальности: как видно на рисунке 1, при высоком уровне ви-

Таблица 4

Вклад оценки кризиса в удовлетворенность жизнью и витальность: независимый от личностных ресурсов потенциала и опосредствованный личностными ресурсами (результаты анализа модерации)

\begin{tabular}{|c|c|c|c|c|}
\hline \multirow{3}{*}{ Переменные в модели } & \multicolumn{4}{|c|}{ Зависимая переменная } \\
\hline & \multicolumn{2}{|c|}{$\begin{array}{l}\text { Удовлетворенность } \\
\text { жизнью - замер } 2\end{array}$} & \multicolumn{2}{|c|}{$\begin{array}{l}\text { Витальность - } \\
\quad \text { замер } 2\end{array}$} \\
\hline & $\triangle R^{2}$ & $\beta$ & $\triangle R^{2}$ & $\beta$ \\
\hline $\begin{array}{l}\text { Шаг } 1 \\
\text { Зависимая переменная - замер } 1\end{array}$ & $.53^{* *}$ & $.72^{* *}$ & $.19^{* *}$ & $.43^{* *}$ \\
\hline $\begin{array}{l}\text { Шаг } 2 \\
\text { Зависимая переменная - замер } 1 \\
\text { Оценка кризиса }\end{array}$ & .00 & $\begin{array}{l}.72^{* *} \\
-.02\end{array}$ & .01 & $\begin{array}{l}.41^{* *} \\
-.12\end{array}$ \\
\hline $\begin{array}{l}\text { Шаг } 3 \\
\text { Зависимая переменная - замер } 1 \\
\text { Оценка кризиса } \\
\text { Взаимодействие зависимой переменной - } \\
\text { замер } 1 \text { и оценки кризиса }\end{array}$ & .00 & $\begin{array}{l}.67 * * \\
-.15 \\
.13\end{array}$ & $.04^{\mathrm{T}}$ & $\begin{array}{c}.14 \\
-.96^{*} \\
.85^{\mathrm{T}}\end{array}$ \\
\hline $\begin{array}{l}\text { Шаг } 4 \\
\text { Зависимая переменная - замер } 1 \\
\text { Оценка кризиса } \\
\text { Взаимодействие зависимой переменной - } \\
\text { замер } 1 \text { и оценки кризиса } \\
\text { Личностные ресурсы }\end{array}$ & .01 & $\begin{array}{r}.68 \\
-.23 \\
.21 \\
-.09\end{array}$ & $.06^{* *}$ & $\begin{array}{r}.02 \\
-.82^{\mathrm{T}} \\
.73^{\mathrm{T}} \\
.30^{*}\end{array}$ \\
\hline $\begin{array}{l}\text { Шаг } 5 \\
\text { Зависимая переменная - замер } 1 \\
\text { Оценка кризиса } \\
\text { Взаимодействие зависимой переменной - } \\
\text { замер } 1 \text { и оценки кризиса } \\
\text { Личностные ресурсы } \\
\text { Взаимодействие личностных ресурсов и } \\
\text { оценки кризиса }\end{array}$ & $.03^{*}$ & $\begin{array}{l}.75^{* *} \\
-.02 \\
-.07 \\
-.47^{*} \\
.45^{*}\end{array}$ & .00 & $\begin{array}{c}.01 \\
-.90^{\mathrm{T}} \\
\\
.82^{\mathrm{T}} \\
.40 \\
-.08\end{array}$ \\
\hline $\begin{array}{l}\text { Общий процент объясняемой } \\
\text { дисперсии } R^{2}\end{array}$ & & & & $* *$ \\
\hline
\end{tabular}

${ }^{\mathrm{T}} p<0.1,{ }^{*} p<0.05,{ }^{* *} p<0.01$. 
тальности субъективная оценка кризиса практически не сказывается на дальнейших ее изменениях; при низком изначальном уровне витальности представление, что кризис сказался на жизни человека, приводит к снижению витальности.

Личностные ресурсы вносят дополнительный независимый вклад в уровень витальности респондентов через год - этот эффект не зависит ни от исходного уровня витальности, ни от оценки кризиса.
Наконец, на последнем шаге регрессионного анализа отмечается значимое (хотя и небольшое) увеличение процента объясняемой дисперсии в предсказании удовлетворенности жизнью. Для иллюстрации данного эффекта мы разделили респондентов в зависимости от уровня личностных ресурсов по медиане на две группы: как видно на рисунке 2, при низком уровне личностных ресурсов удовлетворенность жизнью через год значительно сильнее зависит от

Рисунок 1

Вклад витальности при первом замере и субъективной оценки кризиса в уровень витальности через год

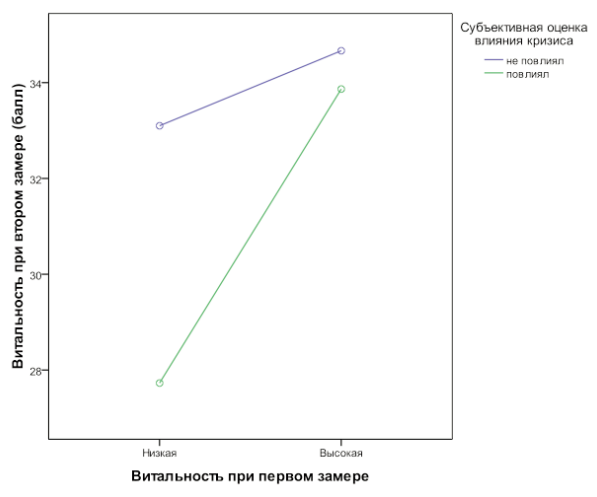

Рисунок 2

Вклад личностных ресурсов при первом замере и субъективной оценки кризиса в удовлетворенность жизнью через год

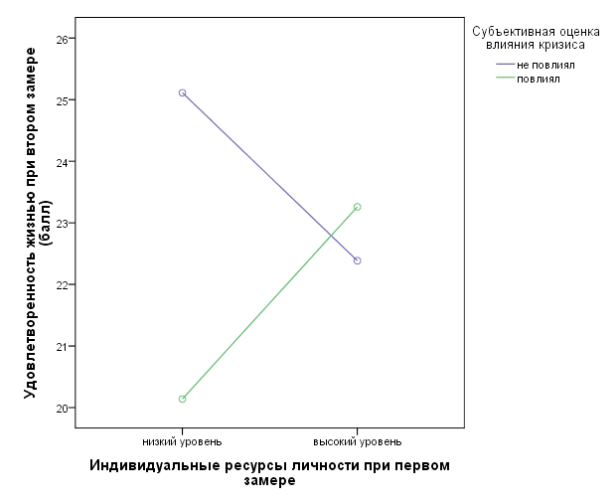


оценки кризиса, чем при высоком его уровне. Более того, при высоком уровне личностных ресурсов удовлетворенность жизнью при втором замере парадоксально выше у тех, кто считает, что кризис повлиял на их жизнь.

\section{Обсуждение результатов}

\section{Субъективнье критерии и психо-} логические факторы оценки влияния кризиса на жизнь: фильтрующая функция. Согласно полученным в рамках первого замера результатам, оценка влияния кризиса связана с представлениями об изменениях, произошедших в профессиональной, финансовой сферах, с возможностями отдыха и самочувствием, однако ни один из этих показателей не определяет оценку респондентами влияния кризиса полностью. Это ставит вопросы о выборе критериев и протекании процесса оценивания, в том числе в какой степени они зависят от личностных ресурсов, - что является задачей дальнейших, в особенности качественных исследований. В соответствии с первым предположением субъективный вывод о наличии или отсутствии влияния кризиса на жизнь человека не зависит от социодемографических факторов и лишь в минимальной степени определяется личностными ресурсами (значимые эффекты получены в отношении осмысленности своей жизни как процесса и как результата). Тем не менее негативная оценка влияния кризиса связана с более низкой удовлетворенностью жизнью и витальностью. Иными словами, мы получили слабые свидетельства в пользу фильтрующей функции личностных ресур- сов, которые требуют дальнейшей проверки в исследованиях. Можно предполагать более дифференцированное влияние личностных ресурсов на оценку ситуации: в частности, более высокий уровень самоконтроля может способствовать более внимательному отношению к кризису, беспокойству по поводу его последствий и превентивному совладанию (Schwarzer, Knoll, 2002). Однако дизайн данного исследования не позволяет развести собственно фильтрующую функцию личностных ресурсов, функцию регуляции эмоционального состояния (например, «паники» вследствие тревожных ожиданий) и функцию совладания с трудностями (активное совладание, превентивное совладание и т.п.).

Вклад личностных ресурсов в динамику субъективного благополучия при разной оченке влияния кризиса на жизнь: буферная функция. По результатам первого замера, вклады личностных ресурсов и оценки влияния кризиса были относительно независимы; значимого влияния взаимодействия (т.е. буферного эффекта) выявлено не было. Однако в отношении динамики субъективного благополучия через год картина была иной. Так, после статистического контроля удовлетворенности жизнью при первом замере удовлетворенность жизнью через год зависела от соотношения личностных ресурсов и субъективной оценки кризиса: при низком уровне личностных ресурсов удовлетворенность жизнью через год больше зависела от оценки кризиса, чем при высоких личностных ресурсах; при низком уровне личностных ресурсов признание влияния кризиса на жизнь было связано с более 
низким уровнем удовлетворенности, тогда как при высоком уровне с более высоким. Иными словами, как можно было ожидать, при благоприятной в целом ситуации личностные ресурсы не играют большой роли, однако при неблагоприятной ситуации их выраженность оказывается существенным фактором, влияющим на психологическое благополучие, что свидетельствует в пользу гипотезы о буферной функции личностных ресурсов в отношении удовлетворенности жизнью. Что касается витальности, то ее уровень при втором замере зависел от личностных ресурсов в начале исследования; и этот эффект не был опосредствован особенностями оценки кризиса. Можно предполагать, что изменения в уровне витальности определяются не учтенными в данной модели факторами (общий итоговый процент объясняемой дисперсии - 30\%). Тот факт, что эффекты, выявленные при анализе модерации, значимые, но небольшие (2-6\% дисперсии), делает необходимым обсуждение вопроса о практических следствиях из полученных результатов. Здесь важно учесть, что многочисленные данные о том, что и благополучие, и поведение человека во многом определяются благополучием и поведением в прошлом, никак не способствуют пониманию того, каким образом и в каких случаях благополучие и поведение все-таки изменяются. В этом смысле даже небольшие изменения в модели уточняют понимание собственно психологической структуры этих изменений и позволяют предпо- лагать возможные пути помощи в стрессогенных ситуациях.

\section{Выводы}

Таким образом, согласно полученным данным, гипотеза о фильтрующей функции личностных ресурсов в отношении оценки влияния экономического кризиса подтверждается лишь частично в отношении переживания осмысленности своей жизни. При этом можно предполагать, что различные психологические факторы вносят специфический вклад в оценку кризиса и их роль может быть неоднозначной: так, респонденты с высоким уровнем осмысленности жизни, но низким уровнем самоконтроля реже считают, что кризис сказался на их жизни.

Буферная функция личностных ресурсов отчетливо проявилась в отношении удовлетворенности жизнью через год, но не витальности, что позволяет предполагать, что реализация буферной функции требует продолжительного времени и зависит от того, о какой составляющей субъективного благополучия идет речь. По всей видимости, витальность в целом в меньшей степени зависит от оценки кризиса и, хотя и тесно связана с личностными ресурсами, определяется и другими факторами.

В целом полученные данные поддерживают общую гипотезу о том, что в зависимости от специфической ситуации и особенностей саморегуляции личностные ресурсы могут выполнять различные функции (Леонтьев, 2011; Рассказова, 2011). 


\section{Литература}

Александрова, Л. А. (2011). Субъективная витальность как составляющая личностного потенциала. В кн. Д. А. Леонтьев (ред.), Личнотный потенщиал: структура и диагностика (с. 382-403). М.: Смысл.

Бодров, В. А. (2000). Роль личностных особенностей в развитии психологического стресса. В кн. Психические состояния. Хрестоматия. СПб.: Питер.

Василюк, Ф. Е. (1984). Психология переживания. Анализ преодоления критических ситуащий. М.: Изд-во Московского университета.

Вассерман, Л. И., Иовлев, Б. В., Исаева, Е. Р., Трифонова, Е. А., Щелкова, О. Ю., Новожилова, М. Ю., Вукс, А. Я. (2009). Методика психологической диагностики способов совладания со стрессовыми и проблемными для личности ситуащиями. СПб.: Психоневрологический институт им. В.М. Бехтерева.

Водопьянова, Н. Е. (2009). Психодиагностика стресса. Серия «Практикум». СПб.: Питер.

Гордеева, Т. О., Сычев, О. А., Осин, Е. Н. (2010). Разработка русскоязычной версии теста диспозиционного оптимизма (LOT). Психологическая диагностика, 2, 36-64.

Демин, А. Н. (2004). Личность в кризисе занятости: стратегии и механизмы преодоления кризиса. Краснодар: Кубанский государственный университет.

Зейгарник, Б. В., Холмогорова, А. Б., Мазур, Е. С. (1989). Саморегуляция поведения в норме и патологии. Психологический журнал, 10(2), 122-131.

Ибрагимова, Д. Х., Кузина, О. Е. (2009). Финансовое поведение населения России в условиях кризиса. Аналитика ЛЭСИ, 5, 6-39.

Крюкова, Т. Л. (2004). Психология совладающего поведения: Монография. Кострома: Студия оперативной полиграфии «Авантитул».

Лазарус, Р. С. (1970). Теория стресса и психофизиологические исследования. В кн. Л. Леви (ред.), Эмоциональный стресс. Л.: Медицина,

Леонтьев, Д. А. (1992). Тест смысложизненных ориентаций (СЖО). М.: Смысл.

Леонтьев, Д. А. (2011). Личностный потенциал как потенциал саморегуляции. В кн. Д. А. Леонтьев (ред.), Личностный потенциал: структура и диагностика (с. 107-130). М.: Смысл.

Леонтьев, Д. А., Рассказова, Е. И. (2006). Тест жизнестойкости. М.: Смысл.

Луковицкая, Е. Г. (1998). Социально-психологчческое значение толерантности $к$ неопределенности (Кандидатская диссертация, Санкт-Петербургский государственный университет, Санкт-Петербург).

Муздыбаев, К. (1998). Стратегия совладания с жизненными трудностями. Журнал социологии и социальной антропологии, 1(2), 102-112.

Муздыбаев, К. (2001). Переживание бедности как социальной неудачи: атрибуция ответственности, стратегии совладания и индикаторы депривации. Сощиологический журнал, 1, 4-25.

Наследов, А. Д. (2004). Математические методы в психологии. СПб.: Речь.

Осин, Е. Н., Леонтьев, Д. А. (2008). Апробация русскоязычных версий двух шкал экспресс-оценки субъективного благополучия. В кн. Материаль III Всероссийского сочиологического конгресса. М.: Институт социологии РАН; Российское общество социологов.

Рассказова, Е. И. (2011). Психологические факторы саморегуляции на разных этапах выполнения учебного задания. Психологический журнал, 32(2), 36-47.

Сергиенко, Е. А. (2009). Контроль поведения: индивидуальные ресурсы субъектной регуляции. Психологические исследования: электронный научный журнал, 5(7). Режим доступа: http://psystudy.ru (дата обращения: 10.07.2015). 
Тиллих, П. (1995). Мужество быть. В кн. П. Тиллих, Избранное. Теология культуры (с. 7-132). М.: Юрист.

Франкл, В. (1990). Человек в поисках смысла. М.: Прогресс.

Шварцер, Р., Ерусалем, М., Ромек, В. (1996). Русская версия шкалы общей самоэффективности Р. Шварцера и М. Ерусалема. Иностранная психология, 7, 71-77.

Baltes, P. B. (1987). Theoretical propositions of life Spain developmental psychology: On the dynamics between growth and decline. Developmental Psychology, 23, 611-626.

Baumeister, R. F., Schmeichel, B. J., \& Vohs, K. D. (2007). Self-regulation and executive function: The Self as controlling agent. In A. W. Kruglanski \& E. T. Higgins (Eds.), Social psychology: Handbook of basic principles (pp. 516-539). New York: Guilford Press.

Benight, C. C., \& Harper, M. L. (2002). Coping self-efficacy perceptions as a mediator between acute stress response and long-term distress following natural disasters. Journal of Traumatic Stress, 15(3), 177-186.

Cole, K., Daly, A., \& Mak, A. (2009). Good for the soul: The relationship between work, wellbeing and psychological capital. The Journal of Socio-Economics, 28, 464-474.

Culbertson, S., Fullagar, C. J., \& Mills, M. J. (2010). Feeling good and doing great: The relationship between psychological capital and well-being. Journal of Occupational Health Psychology, 15(4), 421-433.

Diener, E., Emmons, R. A., Larsen, R. J., \& Griffin, S. (1985). The Satisfaction With Life Scale. Journal of Personality Assessment, 49, 71-75.

Field, A. (2005). Discovering statistics using SPSS. London: Sage Publications.

Folkman, S., Schaefer, C., \& Lazarus, R. (1979). Cognitive processes as mediators of stress and coping IV. In V. Hamilton \& D. M. Warburton (Ed.), Human stress and cognition: an information-processing approach (pp. 265-298). London: John Wiley and Sons Ltd.

Grumer, S., \& Pinquart, M. (2011). Perceived changes in personal circumstances related to social change. European Psychologist, 16(1), 68-78.

Hobfoll, S. (2011). Conservation of resources theory: its implication for stress, health, and resilience. In S. Folkman (Ed.), The Oxford handbook of stress, health, and coping (pp. 127-147). New York: Oxford University Press.

Holahan, C. J., \& Moos, R. H. (1991). Life stressor, personal and social resources and depression: a 4year structural model. Journal of Abnormal Psychology, 100(1), 31-38.

Ironson, G., Wynings, C., Schneiderman, N., Baum, A., Rodriguez, M., Greenwood D., Fletcher, M. A. (1997). Post-traumatic stress symptoms, intrusive thoughts, loss, and immune function after Hurricane Andrew. Psychosomatic Medicine, 59, 128-141.

Jerusalem, M., \& Schwarzer, R. (1992). Self-efficacy as a resource factor in stress appraisal processes. In R. Schwarzer (Ed.), Self-efficacy: Thought control of action (pp. 195-213). New York: Hemisphere.

Lazarus, R. (2006). Emotions and interpersonal relationships: toward a person-centered conceptualization of emotions and coping. Journal of Personality, 74(1), 9-43.

Lazarus, R., \& Folkman, S. (1984). Stress, appraisal and coping. New York: Springer.

Luthans, F., Steven, M., Bruce, J., Avolio, N., \& Avey, J. (2008). The mediating role of psychological capital in the supportive organizational climate-employee performance relationship. Journal of Organizational Behavior, 29(2), 219-238.

Maddi, S. R. (1987). Hardiness training at Illinois Bell Telephone. In J. P. Opatz (Ed.), Health promotion evaluation (pp. 101-115). Stevens Point, WI: National Wellness Institute.

Maddi, S. (2001). The story of hardiness: 20 years of theorizing, research and practice. Consulting Psychology Journal, 54, 173-185. 
Maddi, S. R., \& Koshaba, D. M. (1984). Resilience at work: How to succeed no matter what life throws at you. New York: AMACOM.

Maddi, S. R., \& Khoshaba, D. M. (2001). Personal Viewes Survey III-R: Test development and internet instruction manual. Newport Beach, CA: Hardiness Institute.

Mastenbroek, N. J. J. M., Jaarsma, A. D. C., Scherpbier, A. J. J. A., Beukelen, P. van, \& Demerouti, E. (2014). The role of personal resources in explaining well-being and objective performance: a study among young veterinary professionals. European Journal of Work and Organizational Psychology, 23(2), 190-202.

McLain, D. L. (1993). The MSTAT-I: A new measure of an individual's tolerance for ambiguity. Educational and Psychological Measurement, 53(1), 183-189.

Ryan, R. M., \& Frederick, C. M. (1997). On energy, personality and health: Subjective vitality as a dynamic reflection of well-being. Journal of Personality, 65, 529-565.

Scheier, M. F., \& Carver, C. S. (1985). Optimism, coping, and health: Assessment and implications of generalized outcome expectancies. Health Psychology, 4(3), 219-247.

Schwarzer, R. (1999). Self-regulatory processes in the adoption and maintenance of health behaviors. The role of optimism, goals, and threats. Journal of Health Psychology, 4, 115-127.

Schwarzer, R., \& Knoll, N. (2002). Positive coping: Mastering demands and searching for meaning. In S. J. Lopez \& C. R. Snyder (Eds.), Handbook of positive psychological assessment (Chapter 25, pp. 393-409). Washington, DC: American Psychological Association.

Shteyn, M., Schumm, J. A., Vodopianova, M., Hobfoll, S. E., \& Lilly, R. (2003). The impact of the Russian transition on psychosocial recourses and psychological distress. Journal of Community Psychology, 31(2), 113-127.

Sirgy, M. J., Michalos, A. C., Ferris, A. L., Easterlin, R. A., Patrick, D., \& Pavot, W. (2006). The quality of life (QOL) research movement: past, present and future. Social Indicators Research, 76, 343-466.

Thoits, P. A. (1994). Stressors and problem-solving: The individual as psychological activist. Journal of Health and Social Behavior, 35, 143-159.

Turner, R. J., Taylor J., \& Gundy, K. (2004). Personal resources and depression in the transition to adulthood: Ethic comparison. Journal of Health and Social Behavior, 45, 34-52.

Wise, D., \& Stake, J. E. (2002). The moderating roles of personal and social resources on the relationship between dual expectations (for instrumentality and expressiveness) and well-being. The Journal of Social Psychology, 142(1), 109-119.

Xanthopoulou, D., Bakker, A. B., Demerouti, E., \& Schaufeli, W. B. (2007). The role of personal resources in the job demands-resources model. International Journal of Stress Management, 14, 121-141.

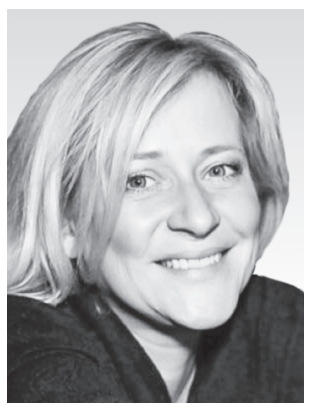

Иванова Татьяна Юрьевна - научный сотрудник, Международная лаборатория позитивной психологии личности и мотивации, факультет социальных наук, департамент психологии, Национальный исследовательский университет «Высшая школа экономики». Контакты: Tatiana.y.ivanova@gmail.com 

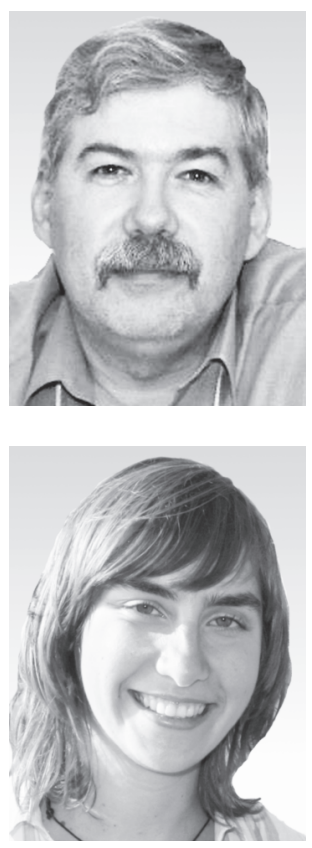

Леонтьев Дмитрий Алексеевич - заведующий лабораторией, Международная лаборатория позитивной психологии личности и мотивации, факультет социальных наук, департамент психологии, Национальный исследовательский университет «Высшая школа экономики», доктор психологических наук, профессор. Контакты: dmleont@gmail.com

Рассказова Елена Игоревна - ведущий научный сотрудник, Международная лаборатория позитивной психологии личности и мотивации, факультет социальных наук, департамент психологии, Национальный исследовательский университет «Высшая школа экономики»; доцент, кафедра клинической психологии, Московский государственный университет им. М.В. Ломоносова, кандидат психологических наук.

Контакты: e.i.rasskazova@gmail.com

\title{
Functions of Personality Resources in a Situation of Economic Crisis
}

\author{
Tatiana Yu. Ivanova a , Dmitry A. Leontieva, Elena I. Rasskazovaa,
}

${ }^{a}$ National Research University Higher School of Economics, 20 Myasnitskaya str., Moscow, 101000, Russian Federation

${ }^{b}$ Lomonosov Moscow State University, 1 Leninskie Gory, Moscow, 119991, Russian Federation

\begin{abstract}
The focus of the paper is the contribution of personality resources (optimism, hardiness, tolerance to ambiguity, self-efficacy, purpose in life), to the dynamics of subjective well-being under the pressure of economic crisis. As expected, personality resources have both filtering and buffering functions, influencing the subjective impact of economic crisis upon the life circumstances as well as subjective well-being. 126 adult Muscovites participated in the first wave of the study during the fervor of the crisis in Russia in Spring 2009 filling out the questionnaires addressing personal resources, subjective well-being, vitality, and questions about the impact of economic crisis on their life circumstances. In the second wave 18 months later the levels of subjective well-being and vitality were measured again in 86 of the participants. The results showed that the effect of the economic crisis was associated with personality resources more than with socialdemographic data. The filtering function was revealed only for purpose in life and self-control coping while for hardiness, optimism and planning coping the effect was much weaker. Buffering function showed itself more pointedly than filtering one. Moreover, the buffering function was
\end{abstract}


shown for all the resources separately as well as for integral index of personality resources (IPR). However, buffering function was revealed only regarding the dynamics of subjective well-being as a dependent variable, but not for the dynamics of vitality. In particular, the subjective wellbeing of those who had low level of IPR depended more on the effect of economic crisis than in those who had high level of IPR. Even more, in the second wave for the participants who reported being highly affected by the crisis but had a high level of IPR showed high level of subjective well-being.

Keywords: personality resources, subjective estimation of the affect of economic crisis, buffering function of personality resources, dynamics of subjective well-being.

\section{References}

Aleksandrova, L. A. (2011). Sub”ektivnaya vital'nost' kak sostavlyayushchaya lichnostnogo potentsiala [Subjective vitality as a component of personal potential]. In D. A. Leontiev (Ed.), Lichnostnyi potentsial: struktura i diagnostika [Personal potential: Structure and diagnostics] (pp. 382-403). Moscow: Smysl.

Baltes, P. B. (1987). Theoretical propositions of life Spain developmental psychology: On the dynamics between growth and decline. Developmental Psychology, 23, 611-626.

Baumeister, R. F., Schmeichel, B. J., \& Vohs, K. D. (2007). Self-regulation and executive function: The Self as controlling agent. In A. W. Kruglanski \& E. T. Higgins (Eds.), Social psychology: Handbook of basic principles (pp. 516-539). New York: Guilford Press.

Benight, C. C., \& Harper, M. L. (2002). Coping self-efficacy perceptions as a mediator between acute stress response and long-term distress following natural disasters. Journal of Traumatic Stress, 15(3), 177-186.

Bodrov, V. A. (2000). Rol' lichnostnykh osobennostei v razvitii psikhologicheskogo stressa [The role of personal characteristics in development of psychological stress]. In Psikhicheskie sostoyaniya. Khrestomatiya [Psychic states. A reading book]. Saint Petersburg: Piter.

Cole, K., Daly, A., \& Mak, A. (2009). Good for the soul: The relationship between work, wellbeing and psychological capital. The Journal of Socio-Economics, 28, 464-474.

Culbertson, S., Fullagar, C. J., \& Mills, M. J. (2010). Feeling good and doing great: The relationship between psychological capital and well-being. Journal of Occupational Health Psychology, 15(4), 421-433.

Demin, A. N. (2004). Lichnost'v krizise zanyatosti: strategii i mekhanizmy preodoleniya krizisa [Personality in an employment crisis: Strategies and mechanisms of coping with crisis]. Krasnodar: Kuban State University.

Diener, E., Emmons, R. A., Larsen, R. J., \& Griffin, S. (1985). The Satisfaction With Life Scale. Journal of Personality Assessment, 49, 71-75.

Field, A. (2005). Discovering statistics using SPSS. London: Sage Publications.

Folkman, S., Schaefer, C., \& Lazarus, R. (1979). Cognitive processes as mediators of stress and coping IV. In V. Hamilton \& D. M. Warburton (Ed.), Human stress and cognition: an information-processing approach (pp. 265-298). London: John Wiley and Sons Ltd.

Frankl, V. (1990). Chelovek v poiskakh smysla [Man in search of meaning]. Moscow: Progress. (Transl. of: Frankl, V. (1972). Der Mensch auf der Suche nach Sinn. Stuttgart: Klett. (in German))

Gordeeva, T. O., Sychev, O. A., \& Osin, E. N. (2010). Razrabotka russkoyazychnoi versii testa dispozitsionnogo optimizma (LOT) [The development of a Russian version of the test of dispositional optimism (LOT)]. Psikhologicheskaya Diagnostika, 2, 36-64. 
Grumer, S., \& Pinquart, M. (2011). Perceived changes in personal circumstances related to social change. European Psychologist, 16(1), 68-78.

Hobfoll, S. (2011). Conservation of resources theory: its implication for stress, health, and resilience. In S. Folkman (Ed.), The Oxford handbook of stress, health, and coping (pp. 127-147). New York: Oxford University Press.

Holahan, C. J., \& Moos, R. H. (1991). Life stressor, personal and social resources and depression: a 4year structural model. Journal of Abnormal Psychology, 100(1), 31-38.

Ibragimova, D. Kh., \& Kuzina, O. E. (2009). Finansovoe povedenie naseleniya Rossii v usloviyakh krizisa [Financial behavior of Russian population in conditions of crisis]. Analitika LESI, 5, 6-39.

Ironson, G., Wynings, C., Schneiderman, N., Baum, A., Rodriguez, M., Greenwood D., Fletcher, M. A. (1997). Post-traumatic stress symptoms, intrusive thoughts, loss, and immune function after Hurricane Andrew. Psychosomatic Medicine, 59, 128-141.

Jerusalem, M., \& Schwarzer, R. (1992). Self-efficacy as a resource factor in stress appraisal processes. In R. Schwarzer (Ed.), Self-efficacy: Thought control of action (pp. 195-213). New York: Hemisphere.

Kryukova, T. L. (2004). Psikhologiya sovladayushchego povedeniya: Monografiya [The psychology of coping behavior: Monograph]. Kostroma: Avantitul.

Lazarus R.C. (1970). Theory of Stress and psychological research. In L. Levi (Ed.), Emotional stress. Leningrad: Medicina.

Lazarus, R. (2006). Emotions and interpersonal relationships: toward a person-centered conceptualization of emotions and coping. Journal of Personality, 74(1), 9-43.

Lazarus, R., \& Folkman, S. (1984). Stress, appraisal and coping. New York: Springer.

Leontiev, D.A. (2011). Personal potential as self-regulation potential. In D. A. Leontiev (Ed.), Lichnostnyi potentsial: struktura i diagnostika [Personal potential: Structure and diagnostics] (pp. 107-130). Moscow: Smysl.

Leontiev, D. A. (1992). Test smyslozhiznennykh orientatsii (SZhO) [Life meaning orientations test]. Moscow: Smysl.

Leontiev, D. A. (2011). Lichnostnyi potentsial kak potentsial samoregulyatsii [Personal potential as self-regulation potential]. In D. A. Leontiev (Ed.), Lichnostnyi potentsial: struktura i diagnostika [Personal potential: Structure and diagnostics] (pp. 107-130). Moscow: Smysl.

Leontiev, D. A., \& Rasskazova, E. I. (2006). Test zhiznestoikosti [Hardiness test]. Moscow: Smysl.

Lukovitskaya, E. G. (1998). Sotsial'no-psikhologicheskoe znachenie tolerantnosti $k$ neopredelennosti [Social psychological meaning of tolerance to ambiguity] ( $\mathrm{PhD}$ disertation, Saint Petersburg State University, Saint Petersburg, Russian Federation).

Luthans, F., Steven, M., Bruce, J., Avolio, N., \& Avey, J. (2008). The mediating role of psychological capital in the supportive organizational climate-employee performance relationship. Journal of Organizational Behavior, 29(2), 219-238.

Maddi, S. (2001). The story of hardiness: 20 years of theorizing, research and practice. Consulting Psychology Journal, 54, 173-185.

Maddi, S. R. (1987). Hardiness training at Illinois Bell Telephone. In J. P. Opatz (Ed.), Health promotion evaluation (pp. 101-115). Stevens Point, WI: National Wellness Institute.

Maddi, S. R., \& Koshaba, D. M. (1984). Resilience at work: How to succeed no matter what life throws at you. New York: AMACOM.

Maddi, S. R., \& Khoshaba, D. M. (2001). Personal Viezes Survey III-R: Test development and internet instruction manual. Newport Beach, CA: Hardiness Institute. 
Mastenbroek, N. J. J. M., Jaarsma, A. D. C., Scherpbier, A. J. J. A., Beukelen, P. van, \& Demerouti, E. (2014). The role of personal resources in explaining well-being and objective performance: a study among young veterinary professionals. European Journal of Work and Organizational Psychology, 23(2), 190-202.

McLain, D. L. (1993). The MSTAT-I: A new measure of an individual's tolerance for ambiguity. Educational and Psychological Measurement, 53(1), 183-189.

Muzdybayev, K. (1998). Strategiya sovladaniya s zhiznennymi trudnostyami. Zhurnal Sotsiologii i Sotsial'noi Antropologii, 1(2), 102-112.

Muzdybayev, K. (2001). The feelings of poverty as a social failure: The attribution of responsibility, and indicators of deprivation. Sotsiologicheskii Zhurnal, 1, 4-25.

Nasledov, A. D. (2004). Matematicheskie metody v psikhologii [Mathematical methods in psychology]. Saint Petersburg: Rech'.

Osin, E. N., \& Leontiev, D. A. (2008). Aprobatsiya russkoyazychnykh versii dvukh shkal ekspressotsenki sub" ektivnogo blagopoluchiya [Approbation of Russian versions of two scales for expressevaluation of subjective wellbeing]. In Materialy III Vserossiiskogo sotsiologicheskogo kongressa [Proceedings of the Third All-Russian sociological congress]. Moscow: Institute of Sociology of Russian Academy of Sciences; Russian Society of Sociologists.

Rasskazova, E. I. (2011). Psychological factors of self regulation at different stages of educational task's fulfillment. Psikhologicheskii Zhurnal, 32(2), 36-47.

Ryan, R. M., \& Frederick, C. M. (1997). On energy, personality and health: Subjective vitality as a dynamic reflection of well-being. Journal of Personality, 65, 529-565.

Scheier, M. F., \& Carver, C. S. (1985). Optimism, coping, and health: Assessment and implications of generalized outcome expectancies. Health Psychology, 4(3), 219-247.

Schwarzer, R. (1999). Self-regulatory processes in the adoption and maintenance of health behaviors. The role of optimism, goals, and threats. Journal of Health Psychology, 4, 115-127.

Schwarzer, R., \& Knoll, N. (2002). Positive coping: Mastering demands and searching for meaning. In S. J. Lopez \& C. R. Snyder (Eds.), Handbook of positive psychological assessment (Chapter 25, pp. 393-409). Washington, DC: American Psychological Association.

Schwarzer, R., Jerusalem, M., \& Romek, V. (1996). Russkaya versiya shkaly obshchei samoeffektivnosti R. Shvartsera i M. Erusalema [Russian version of the general self-efficiency scale by R.Schwarzer and M. Jerusalem]. Inostrannaya Psikhologiya, 7, 71-77.

Sergienko, E. A. (2009). Behavior control: individual resources of subject control. Psikhologicheskie Issledovaniya, 5(7). Retrieved from http://psystudy.ru

Shteyn, M., Schumm, J. A., Vodopianova, M., Hobfoll, S. E., \& Lilly, R. (2003). The impact of the Russian transition on psychosocial recourses and psychological distress. Journal of Community Psychology, 31(2), 113-127.

Sirgy, M. J., Michalos, A. C., Ferris, A. L., Easterlin, R. A., Patrick, D., \& Pavot, W. (2006). The quality of life (QOL) research movement: past, present and future. Social Indicators Research, 76, 343-466.

Thoits, P. A. (1994). Stressors and problem-solving: The individual as psychological activist. Journal of Health and Social Behavior, 35, 143-159.

Tillich, P. (1952). The courage to be. New Haven, CT/London: Yale University Press.

Turner, R. J., Taylor J., \& Gundy, K. (2004). Personal resources and depression in the transition to adulthood: Ethic comparison. Journal of Health and Social Behavior, 45, 34-52. 
Vasilyuk, F. E. (1984). Psikhologiya perezhivaniya. Analiz preodoleniya kriticheskikh situatsii [The psychology of experiencing. Analysis of resolution of life's critical situations]. Moscow: Moscow University Press.

Vasserman, L. I., Iovlev, B. V., Isaeva, E. R., Trifonova, E. A., Shchelkova, O. Yu., Novozhilova, M. Yu., \& Vuks, A. Ya. (2009). Metodika psikhologicheskoi diagnostiki sposobov sovladaniya so stressovymi $i$ problemnymi dlya lichnosti situatsiyami [A technique of psychological diagnostics of coping with situations, which are stressful and problematic for personality]. Saint Petersburg: Saint Petersburg Bekhterev Psychoneurological Research Institute.

Vodopianova, N. E. (2009). Psikhodiagnostika stressa. Seriya "Praktikum" [The psychodiagnostics of stress. Series 'Practicum']. Saint Petersburg: Piter.

Wise, D., \& Stake, J. E. (2002). The moderating roles of personal and social resources on the relationship between dual expectations (for instrumentality and expressiveness) and well-being. The Journal of Social Psychology, 142(1), 109-119.

Xanthopoulou, D., Bakker, A. B., Demerouti, E., \& Schaufeli, W. B. (2007). The role of personal resources in the job demands-resources model. International Journal of Stress Management, 14, 121-141.

Zeigarnik, B. V., Kholmogorova, A. B., \& Mazur, E. S. (1989). Samoregulyatsiya povedeniya v norme i patologii [Self-regulation of behavior in norm and pathology]. Psikhologicheskii Zhurnal, 10(2), 122-131.

Tatiana Yu. Ivanova - research fellow, International Laboratory of Positive Psychology of Personality and Motivation, School of Psychology, Faculty of Social Science, National Research University Higher Scholl of Economics.

E-mail: Tatiana.y.ivanova@gmail.com

Dmitry A. Leontiev - head of International Laboratory of Positive Psychology of Personality and Motivation, School of Psychology, Faculty of Social Science, National Research University Higher School of Economics; D.Sc., professor.

E-mail:dmleont@gmail.com

Elena I. Rasskazova - leading research fellow, International Laboratory of Positive Psychology of Personality and Motivation, School of Psychology, Faculty of Social Science, National Research University Higher School of Economics; professor assistant, department of Clinical Psychology, Lomonosov Moscow State University; Ph.D.

E-mail: e.i.rasskazova@gmail.com 